\title{
An Optimal Selection Method for Product Conceptual Design and Materials Evaluation Based on Quality Function Deployment and Grey Relational Projection
}

\author{
Kailiang Zhu, a , Xiao Wang ${ }^{2, b}$, Yufeng Zhang ${ }^{3, c}$, Rui Mu ${ }^{1, d}$, Shupeng Wang ${ }^{2, e^{*}}$ \\ ${ }^{1}$ Department of Mechanical and Electrical engineering, Xiamen University, Xiamen, China \\ ${ }^{2}$ College of Computer Science, Haerbin Finance University, Haerbin, China \\ ${ }^{3}$ Department of Physics, Xiamen University, Xiamen, China \\ akailiang816@qq.com, b33422521@qq.com,,yufengzhang@xmu.edu.cn, \\ dmurui@xmu.edu.cn, ${ }^{\mathrm{e}} 13804620 @ q q . c o m$
}

Keywords: QFD, Grey relational projection, Materials evaluation, Conceptual design, AHP.

\begin{abstract}
Quality Function Deployment (QFD) is widely used in optimizing schemes (e.g., product designs and materials evaluation). However, the traditional QFD focuses only on the demands of quality and measures to assure the quality. Furthermore, the general methods to evaluate the weight of factors used in QFD include much of subjective aspect, which could introduce bias to the outcomes. This paper proposes an innovative systematic approach for optimal selection, which could be incorporated with global trends in manufacturing (e.g., remanufacturing, green manufacturing), materials research (e.g., eco-friendly plastics), and beyond. First, the traditional QFD is extended to cover the whole lifecycle of products and materials so that the optimization would be comprehensive and consistent with the latest requirements, such as sustainability. Second, the weight of each factor in the improved QFD is derived according to a method based on the combination of analytic hierarchy process (AHP) and entropy theory, which integrates the merit of both subjective and objective methods. Third, an evaluating method originating from grey relational projection is employed to select the best solution from the potential schemes. As an example, the designs of refrigerators are evaluated using the proposed approach. The results suggest that this approach is capable to solve complicated multi-criteria decision-making problem, and be beneficial for much research, including but not limited to product design.
\end{abstract}

\section{Introduction}

A cross-functional planning tool, Quality Function Deployment (QFD), is developed to assist in design of satisfactory products [1]. It is emphasized in QFD that the demands of quality and the measures of guaranteeing the quality should be taken into consideration from the beginning of the product design $[2,3]$. Since the customer requirement can be divided into a hierarchical structure, analytic hierarchy process (AHP) developed by T L Saaty is successfully employed for a wide range of study to hierarchically organize the decision-making process and establish the judging matrix [4-6]. Grey relational analysis (GRA) is a multivariate statistical analysis method, in which relational degree is used to describe the power, size, and order among factors, has been successfully applied in various fields to evaluate schemes with incomplete and uncertain information [7-9]. In this paper, we propose an innovative approach, I-QFD-E, in assisting product design to overcome the disadvantages of current methods. The weight of the factors and sub-factors in the improved-QFD (I-QFD) is derived using AHP and the entropy theory to incorporate the merits of both subjective and objective methods. A grey relational projection is applied to search the best solution from the potential schemes. Finally, the proposed approach is used to design a refrigerator, and shows promising results. 


\section{Methodology}

I-QFD-E Method. Generally, there are $\mathrm{p}$ customer satisfactions namely, $C_{1}, C_{2}, \cdots, C_{p}$, and $\mathrm{m}$ customer requirements $C R_{1}, C R_{2}, \cdots, C R_{m}$. In order to calculate the comprehensive sequencing weight $\alpha_{1}, \alpha_{2}, \cdots, \alpha_{m}$, following steps are taken: firstly, the AHP method is used to determine weight of $\mathrm{p}$ rules, namely $v_{1}, v_{2}, \cdots, v_{p}$. Secondly, the relative weight of $\mathrm{m}$ customer requirements correlating with the $\mathrm{j}_{\text {th }}$ rule is $\rho_{j 1}, \rho_{j 2}, \cdots, \rho_{j m}$. The weight of customer requirements not under the domination of $C_{j}$ is zero. According to the customer requirement sequencing matrix $\rho, \alpha_{k}$ can be expressed as:

$$
\alpha_{k}=\sum_{j=1}^{p} v_{j} \rho_{j k}, \quad k=1,2, \cdots, m
$$

After obtaining the comprehensive sequencing weight of $m$ customer requirements, the $\mathrm{p}$ rules and the customer requirement sequencing hierarchy is under the coherence test. Usually, there are $\mathrm{n}$ design requirements, namely $D R_{1}, D R_{2}, \cdots, D R_{n}$, in the project level. The comprehensive sequencing weight of the total target can be calculated by AHP. The weight of each design requirement oriented to the target level is expressed as $\boldsymbol{\beta}=\left(\beta_{1}, \beta_{2}, \cdots, \beta_{n}\right)$. In this paper, the entropy theory and I-QFD are integrated to form I-QFD-E model, in which the weight of elements in I-QFD is calculated by the entropy theory. The general process of the I-QFD-E model is described here:

Scheme set $\mathrm{S}$ including $\mathrm{m}$ schemes and target set $\mathrm{P}$ including $\mathrm{n}$ targets constitute the multi-attribute decision problem. The decision matrix is:

$$
\mu=\left[\begin{array}{cccc}
\mu_{11} & \mu_{12} & \cdots & \mu_{1 n} \\
\mu_{21} & \mu_{22} & \cdots & \mu_{2 n} \\
\vdots & \vdots & \ddots & \vdots \\
\mu_{m 1} & \mu_{m 2} & \cdots & \mu_{m n}
\end{array}\right]
$$

$\mu_{i j}$ represents the degree of membership of the $\mathrm{j}^{\text {th }}$ target in the $\mathrm{i}^{\text {th }}$ scheme. The larger value of $\mu_{\mathrm{ij}}$ indicates greater contribution of the $\mathrm{j}_{\mathrm{th}}$ target in the $\mathrm{i}_{\mathrm{th}}$ scheme. Information entropy $p_{i j}$ can measure the amount of information delivered by the $\mathrm{j}^{\text {th }}$ target in the $\mathrm{i}^{\text {th }}$ scheme [10].

$$
p_{i j}=\frac{\mu_{i j}}{\sum_{j=1}^{n} \mu_{i j}}(i=1,2, \cdots, m, j=1,2, \cdots, n)
$$

Thus, the entropy of the $\mathrm{j}^{\text {th }}$ target is $e_{j}(j=1,2, \cdots, n)$ :

$$
e_{j}=-k \sum_{i=1}^{m} p_{i j} \ln p_{i j}
$$

where, $k=(\ln n)^{-1}, 0 \leq e_{j} \leq 1$. If $p_{i j}=0$, the value of $p_{i j} \ln p_{i j}$ is set to zero.

The objective weight of the $\mathrm{j}^{\text {th }}$ target is:

$$
\theta_{j}=\frac{1-e_{j}}{\sum_{j=1}^{n}\left(1-e_{j}\right)}
$$

The design requirement weight in I-QFD-E is:

$$
\omega_{j}=\frac{\theta_{j} \cdot \beta_{j}}{\sum_{j=1}^{m}\left(\theta_{j} \cdot \beta_{j}\right)} 0 \leq \omega_{j} \leq 1, \quad \sum_{j=1}^{n} \omega_{j}=1
$$

Product Scheme Evaluation Method of Grey Relational Projection Based on I-QFD-E. The procedures of grey relation projection are:

Step 1: Determining the decision matrix. 


$$
X_{m \times n}=\left[\begin{array}{cccc}
X_{1}(1) & X_{1}(2) & \cdots & X_{1}(n) \\
X_{2}(1) & X_{2}(2) & \cdots & X_{2}(n) \\
\vdots & \vdots & \ddots & \vdots \\
X_{m}(1) & X_{m}(2) & \cdots & X_{m}(n)
\end{array}\right]
$$

Step 2: Making the decision making matrix dimensionless.

To make the value dimensionless, evaluating indicators are categorized into the benefit, cost, and objective criteria. This orients the polarity of matrix to the same direction [11].

Step 3: Determining the reference scheme $X_{0}(n)$ : establishing an optimal scheme as a reference.

Step 4: Determining the grey relational degree.

Step 5: Using the I-QFD-E model to determine the indicator weight.

Step 6: Determining the grey relational projection to assure the direction consistency

(1) Construct grey correlation degree judging matrix

Define $\mathrm{F}$ as the grey correlation degree judging matrix, F can be expressed as:

(2) Grey correlation projection and modulus

$$
\boldsymbol{F}=\left[\begin{array}{cccc}
\gamma_{01} & \gamma_{02} & \cdots & \gamma_{0 n} \\
\gamma_{11} & \gamma_{12} & \cdots & \gamma_{1 n} \\
\vdots & \vdots & \ddots & \vdots \\
\gamma_{m 1} & \gamma_{m 2} & \cdots & \gamma_{m n}
\end{array}\right]
$$

If each potential scheme is treated as a row vector, the cosine of angle between a potential scheme $A_{i}$ and the ideal scheme $A^{*}$ is $r_{i}$ :

$$
r_{i}=\frac{A_{i} \cdot A^{*}}{\left\|A_{i}\right\| \cdot\left\|A^{*}\right\|}=\frac{\sum_{j=1}^{n} \omega_{j} F_{i j} \omega_{j}}{\sqrt{\sum_{j=1}^{n}\left(\omega_{j} F_{i j}\right)^{2}} \sqrt{\sum_{j=1}^{n} \omega_{j}^{2}}}(i=1,2, \cdots, m)
$$

$0 \leq r_{i} \leq 1$ 。 If the $r_{i}$ is bigger, it indicates that both decision scheme and ideal scheme are changing in the same direction [12]. The modulus of decision scheme $A_{i}$ is $d_{i}$ :

$$
d_{i}=\sqrt{\sum_{j=1}^{n}\left(\omega_{j} F_{i j}\right)^{2}}
$$

(3) Calculating the value of grey correlation projection

The proximity between potential and ideal scheme can be completely and accurately reflected by considering modulus and angle [13]. The projection of potential scheme $A_{i}$ on ideal scheme $A^{*}$ is grey relational projection value $D_{i}$, where $D_{i}=d_{i} \cdot r_{i}$. The multiple-indicator schemes can be ranked and analyzed according to the projection value $D_{i}$.

\section{Case Study}

In this paper, the domestic and double-door refrigerators are used as an example. We evaluated four product designs. After analyzing the customer requirements, the corresponding structure of product design requirements is shown in Fig. 1. The total design guidelines are divided into three parts, capabilities, technical, and economic guidelines. The third level is the exact design requirement. 


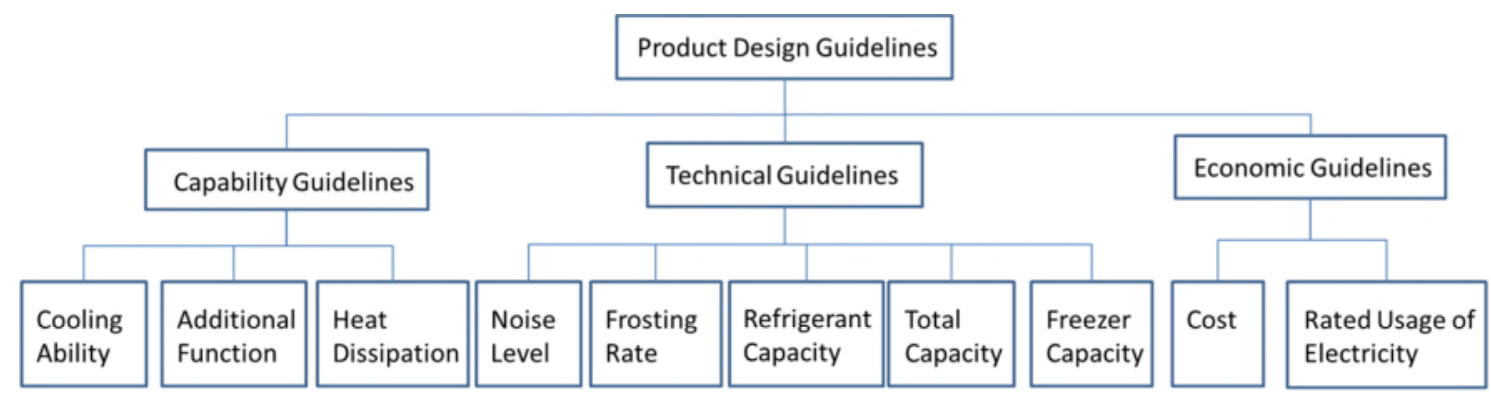

Fig. 1 Schematic diagram of design requirement guidelines.

Through interviewing customers and studying the product currently available, the customer requirements are: high-cooling rate, low electricity usage, low noise level, more functions, low price, and large capacity, are labeled as $\mathrm{CR}_{1}, \mathrm{CR}_{2}, \ldots, \mathrm{CR}_{6}$, respectively. According to the customer requirements, the design requirements are total capacity, refrigerant capacity, freezer capacity, cooling ability, rated usage of electricity, cost, additional function, heat dissipation, noise level, and frosting rate, corresponding to $\mathrm{DR}_{1}, \mathrm{DR}_{2}, \ldots, \mathrm{DR}_{10}$, respectively. Firstly, judging matrix of $\mathrm{CR}$ based on the importance of customer satisfactions is derived according to the theory of AHP. Then design requirement judging matrix oriented to each customer requirement are established, as shown in Table 1.

Table 1. Hierarchical House of Quality of the Refrigerator System.

\begin{tabular}{|c|c|c|c|c|c|c|c|c|c|c|}
\hline $\begin{array}{l}\text { Resign } \\
\text { Customer } \\
\text { Requirements }\end{array}$ & $\begin{array}{c}\text { Total } \\
\text { Capacity }\end{array}$ & $\begin{array}{c}\text { Refrigerant } \\
\text { Capacity }\end{array}$ & $\begin{array}{l}\text { Freezer } \\
\text { Capacity }\end{array}$ & $\begin{array}{c}\text { Cooling } \\
\text { Ability }\end{array}$ & $\begin{array}{c}\text { Rated } \\
\text { Usage of } \\
\text { Electricity }\end{array}$ & Cost & $\begin{array}{l}\text { Additional } \\
\text { Function }\end{array}$ & $\begin{array}{c}\text { Heat } \\
\text { Dissipation }\end{array}$ & $\begin{array}{l}\text { Noise } \\
\text { Level }\end{array}$ & $\begin{array}{c}\text { Frosting } \\
\text { Rate }\end{array}$ \\
\hline High Cooling Rate & 0.408 & 0.042 & 0.042 & 0.042 & 0.298 & 0.054 & 0.053 & 0.059 & 0.117 & 0.128 \\
\hline $\begin{array}{l}\text { Low Electricity } \\
\text { Usage }\end{array}$ & 0.164 & 0.041 & 0.041 & 0.041 & 0.121 & 0.244 & 0.044 & 0.129 & 0.134 & 0.109 \\
\hline Low noise level & 0.101 & 0.043 & 0.043 & 0.043 & 0.093 & 0.061 & 0.052 & 0.121 & 0.14 & 0.284 \\
\hline Additional functions & 0.16 & 0.033 & 0.033 & 0.033 & 0.104 & 0.082 & 0.064 & 0.288 & 0.161 & 0.077 \\
\hline Low price & 0.08 & 0.048 & 0.048 & 0.048 & 0.077 & 0.089 & 0.238 & 0.162 & 0.113 & 0.095 \\
\hline Large capacity & 0.087 & 0.165 & 0.165 & 0.165 & 0.082 & 0.084 & 0.056 & 0.091 & 0.083 & 0.053 \\
\hline $\begin{array}{l}\text { Weight of Design } \\
\text { Requirements }\end{array}$ & 0.052 & 0.052 & 0.052 & 0.181 & 0.096 & 0.068 & 0.124 & 0.126 & 0.123 & 0.125 \\
\hline
\end{tabular}

According to the values in Table 1 and the proposed methodology, the comprehensive weights $\omega_{i}$ of design requirement oriented to total customer satisfaction have been calculated and shown in Table 2, compared to the entropy values $E\left(\omega_{i}\right)$.

Table 2. Comparison of design requirement between entropy value and weight.

\begin{tabular}{|c|c|c|c|c|c|c|c|c|c|c|}
\hline & $\begin{array}{c}\text { Total } \\
\text { Capacity }\end{array}$ & $\begin{array}{c}\text { Refrigerant } \\
\text { Capacity }\end{array}$ & $\begin{array}{c}\text { Freezer } \\
\text { Capacity }\end{array}$ & $\begin{array}{c}\text { Cooling } \\
\text { Ability }\end{array}$ & $\begin{array}{c}\text { Rated Usage } \\
\text { of Electricity }\end{array}$ & Cost & $\begin{array}{c}\text { Additional } \\
\text { Function }\end{array}$ & $\begin{array}{c}\text { Heat } \\
\text { Dissipation }\end{array}$ & $\begin{array}{c}\text { Noise } \\
\text { Level }\end{array}$ & $\begin{array}{c}\text { Frosting } \\
\text { Rate }\end{array}$ \\
\hline$E\left(\omega_{i}\right)$ & 0.998 & 0.996 & 0.999 & 0.900 & 0.989 & 0.999 & 0.994 & 0.989 & 0.906 & 0.906 \\
\hline$\omega_{i}$ & 0.007 & 0.013 & 0.003 & 0.329 & 0.036 & 0.003 & 0.020 & 0.036 & 0.276 & 0.276 \\
\hline
\end{tabular}

We use grey relational projection to evaluate the four schemes, and the results are:

$D_{1}=0.548, D_{2}=0.484, D_{3}=0.335, D_{4}=0.391, D_{5}=0.441$ 
Therefore, the scheme sequence is $1>2>5>4>3$, in which scheme1 is the ideal scheme.

\section{Summary and Conclusion}

In this paper, in order to overcome the disadvantages of traditional QFD methods, we proposed a new model, I-QFD-E, for scheme evaluation and selection that could be especially beneficial for product design and materials evaluation with considerations for sustainability. Firstly, the new model extends the coverage of traditional QFD to the whole lifecycle of products and materials. Secondly, to fully utilize the merit of subjective and objective methods, the weight of factors in I-QFD-E model is determined by a method based on AHP and entropy theory. Thirdly, the quantitative evaluating method originating from grey relational projection overcomes the disadvantages of the traditional GRA, such as usage of the grey relational distinguishing coefficient, improves the scheme selection comprehensively. The new method takes into consideration not only the degree of similarity between the potential schemes and the ideal scheme, but also the direction between the schemes. The evaluation of designs of refrigerators exemplifies the advantages of the new model. Based on the finding, the following conclusions can be derived as: 1 . The proposed model is capableto determine the importance of the technical requirements. Hence, the designed products and materials can satisfy the customers' requirements to the largest extent and meet the demands of sustainable development.2. The proposed method represents the characteristics of the problem more effectively than the traditional methods, and is capable to obtain reliable outcomes. Therefore, the new model is of great assistance for solving the complicate multiple objective decision-making problems, and could be useful for materials evaluation and other research as well.

\section{Acknowledgement}

This work was financially supported by the Fundamental Research Funds for the Central Universities (No. 20720140517 and No. 20720160013), the Scientific Research Project of Heilongjiang Province of China (No. 12541103). The corresponding author is Shupeng Wang.

\section{References}

[1] Z. Sener, E. E. Karsak, A decision model for setting target levels in quality function deployment using nonlinear programming-based fuzzy regression and optimization, Int. J. Adv. Manuf. Technol. 48(9-12) (2010) 1173-1184.

[2] Y. Chen, J. Tang, R. Y. K. Fung, Z. Ren, Fuzzy regression-based mathematical programming model for quality function deployment, Int. J. Prod. Res. 42(5) (2004) 1009-1027.

[3] J. H. Shin, H. B. Jun, D. Kiritsis, P. Xirouchakis, A decision support method for product conceptual design considering product lifecycle factors and resource constraints, Int. J. Adv. Manuf. Technol. 52(9-12) (2011) 865-886.

[4] O. S. Vaidya, S. Kumar, Analytic hierarchy process: An overview of applications, Eur. J. Operational Res. 169(1) (2006) 1-29.

[5] T. L. Saaty, How to make a decision-The analytic hierarchy process, Interface. 24(6) (1994) 19-43.

[6] S. H. Ghodsypour, C. O'Brien, A decision support system for supplier selection using an integrated analytic hierarchy process and linear programming, Int. J. Prod. Econ. 56(7) (1998) 199-212.

[7] K. T. Chiang, The optimal process conditions of an injection-molded thermoplastic part with a thin shell feature using grey-fuzzy logic: A case study on machining the PC/ABS cell phone shell, Mater. Des. 28(6) (2007) 1851-1860. 
[8] C. C. Yang, B. S. Chen, Supplier selection using combined analytical hierarchy process and grey relational analysis, J. Manuf. Technol. Manage. 17(7) (2006) 926-941.

[9] J. Morán, E. Granada, J. L. Míguez, J. Porteiro, Use of grey relational analysis to assess and optimize small biomass boilers, Fuel Pro. Technol. 87(2) (2006) 123-127.

[10]W. H. Qiu, Management Decision and Applied Entropy Theory, Beijing: China Machine Press, 2002, 143-205.

[11]J. L. Deng, Introduction to grey theory system, J. Grey Syst. 1 (1989) 1-24.

[12]G. H. Tzeng, S. H. Tasur, The multiple criteria evaluation of grey relation model, J. Grey Syst. 6 (1994) 87-108.

[13]X. Zhang, F. Jin, P. Liu, A grey relational projection method for multi-attribute decision making based on intuitionistic trapezoidal fuzzy number, Appl. Math. Model. 37 (2013) 3467-3477. 